
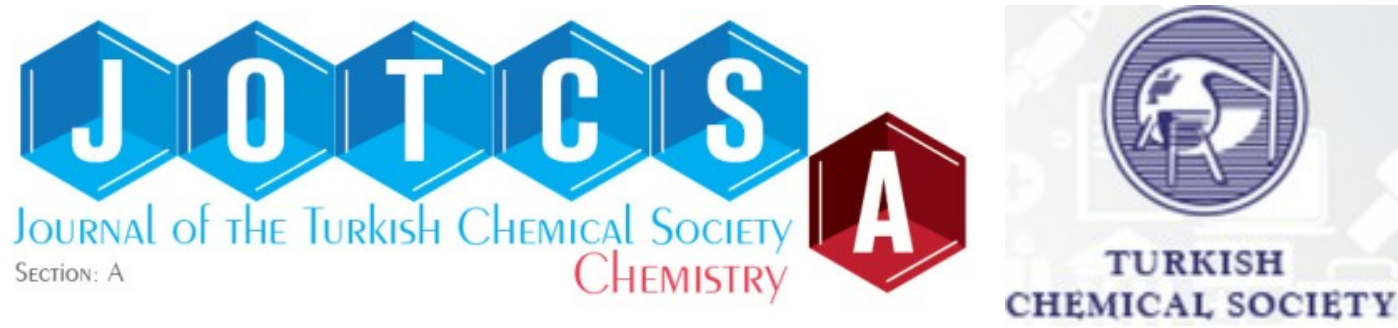

\title{
Extraction and Characterization of Pectin from Lemon Waste for Commercial Applications
}

\author{
Ketema Beyecha Hundie*1 $\triangle$, Desalegn Abdissa Akuma² \\ ${ }^{1,2}$ School of Chemical Engineering, Jimma Institute of Technology, Jimma University, Jimma, Ethiopia
}

\begin{abstract}
The objective of this paper was preliminary to extract and characterization of purified pectin from lemon wastes. Dry lemon waste was extracted applying citric acid solvent or water at various concentrations under a similar condition ( $85^{\circ} \mathrm{C}$ for $4 \mathrm{~h}$ ). It was found that the highest yield of pectin (20.8\% dry basis) was achieved using hot water extraction with an esterification degree of $47.8 \%$. It contained $63.2 \pm 0.74 \%$ galacturonic acid, followed by $17.4 \pm 0.76 \%$ total sugar. The monosaccharides found in pectin were arabinose $(2.7 \pm 0.20 \%)$, galactose $(2.3 \pm 0.01 \%)$, glucose $(1.4 \pm 0.09 \%)$, mannose $(0.4 \pm 0.01 \%)$, fructose $(0.4 \pm 0.05 \%)$, and xylose $(0.1 \pm 0.01 \%)$. The found pectin had a high atomic weight of $2060 \mathrm{kDa}$ with a wide polydispersity index of 4.41, decided by high-Performance Size Exclusion Chromatography (HPSEC). The extricated lemon waste pectin was grouped into low methoxyl pectin, depends on the methoxyl content and degree of esterification affirmed by Fourier transform infrared spectroscopy (FT-IR) and rheological properties. In conclusion, the discoveries of the study show that lemon waste can be investigated as a promising elective for the commercial manufacturing of pectin.
\end{abstract}

Keywords: Lemon waste, pectin, composition, molecular weight

Submitted: March 23, 2021. Accepted: October 21, 2021.

Cite this: Beyecha Hundie K, Abdissa Akuma D. Extraction and Characterization of Pectin from Lemon Waste for Commercial Applications. JOTCSA. 2011;8(4):1111-20.

DOI: https://doi.org/10.18596/jotcsa.901973.

*Corresponding author. E-mail: ketema.hundie@ju.edu.et, Tel: +251913557447.

\section{INTRODUCTION}

Pectin is a complex polysaccharide substance found in the cell walls of plants, including a backbone of a1,4-galacturonic acids that are partly esterified at the carboxylic acid groups and wall and other materials to create a cellulosic network for the firmness of plant tissue (1). It can be commercially extracted from citrus peels and apple pomace with an acidic solution. Several pectin sources have been found in other fruits and vegetables, including okras papayas, cocoa pod husks, and cabbages $(2,3)$. Pectin is widely applied to form a gel and maximize viscosity and constancy in several cosmetic and food industries. It is utilized to prepare jams, jellies, marmalades, and other products to ameliorate the texture. Pectin is also a good dietary fiber, protecting diseases like diabetes and colon cancer in the human body, and letting down cholesterol and serum glucose (4).

The galacturonic acid component units are the primary chain of pectin that is partly linked to neutral sugar side chains. The common carbohydrates found on the ramification chain are galactose, arabinose, and glucose, and to a lesser degree, xylose, mannose, and rhamnose (5). In common, pectin can be divided into two kinds depending on the degree of esterification (DE) high methoxyl pectin (HMP, DE $\geq 50 \%$ ) and low methoxyl pectin (LMP, DE $\leq 50 \%$ ) (6). The gelling formation gotten from HMP at a lower $\mathrm{pH}$ value $(\sim 3)$ within the existence of a large amount of sugar is generally utilized in high sugar jam and jelly-such as a nutrient. In contrast, the gel got from LMP in a higher $\mathrm{pH}$ interval $(2-6)$ with or without a little amount of sugar requires calcium ions for polymer 
interaction and is utilized in low calorie and nonsugar added to nutrient (7).

The amount and properties of pectin vary based on plant sources, extraction mechanism, and extraction stages in the processes. Hot water or acid extractions commonly involved in both the yield and the final quality of the extracted product $(8,9)$. It was detected that the best and optimum extraction parameters to get the most noteworthy pectin from natural citrus products were warm water at $90-110$ ${ }^{\circ} \mathrm{C}$ for $1-5 \mathrm{~h}$ (10). Additionally, it was studied that natural acids such as citric acid in the $\mathrm{pH}$ range of $2.0-2.5$ at higher temperature were excellent solvents for pectin extraction in other natural products (2).

Citrus fruit is the most abundant crop plant in global. Concording to the Food and Agricultural Organization, a lot of $1.17 \times 10^{8}$ tons of citrus fruits (in which lemon leads $0.14 \times 10^{8}$ Tons) were manufactured per year $(11,12)$. The quantity of residual obtained from citrus fruits describes $50 \%$ of the whole fruit's original amount. It has been approximated that, on average, a juice producer forces up to $10.0 \times 10^{4}$ tons of fresh citrus fruits every year and represents the manufacture of the citrus residues as a waste by-product quantity $5.5 \mathrm{x}$ $10^{4}$ tons per year $(14,15)$. Thus, significant quantities of citrus wastes are available as a byproduct. The peels, if addressed as waste materials, may bring environmental problems, especially water pollution. This problem could have become an asset: if possible marketable by-products like pectin could be extracted from these wastes. Previous studies have been investigated the pectin-like and the gel formation ability with calcium cation of the pulp of lemon wastes. Some chemicals and characteristics were also separately studied (16). However, the properties and constitution of purified pectin in its waste have been less delineated.

Therefore, this research directed to a preliminary analysis of pectin extraction from lemon waste and investigated the extracted pectin components and its properties. The data obtained might be advantageous for the practical application of pectin to other items separated from food.

\section{MATERIALS AND METHODS}

\section{Materials}

The lemon wastes were collected from a juice producer in Ethiopia. Galacturonic acid, citrus pectin, and simple sugar (monosaccharide), Bovine serum albumin standard were chemical product suppliers in Addis Ababa, Ethiopia. The citrus pectin with the DE $55-70 \%$ and $85 \%$ as fixed by the provider were applied. Other analytical grade chemicals used in this experiment are not specified. Pectin extraction and characterization were carried out at Addis Ababa University and Jimma institute of technology.

\section{Methodology}

\section{Preparation of lemon wastes}

Lemon wastes were collected as sun-dried, washed, and electric oven-dried. The dry lemon waste (10\% moisture) was scraped, powdered, and passed through a 60 mesh sieve and then stored in a sealed plastic bag at $4{ }^{\circ} \mathrm{C}$ for the subsequent analysis.

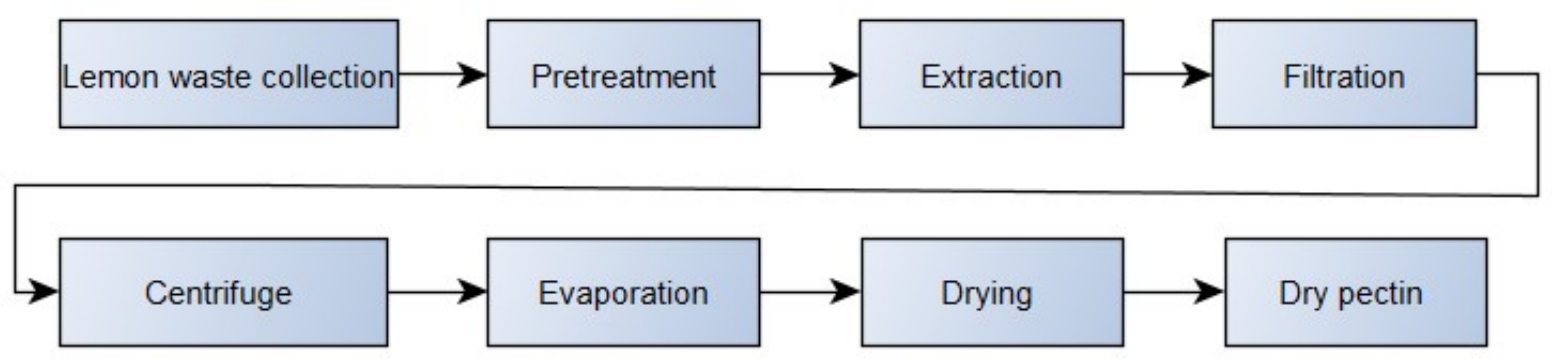

Figure 1: Lemon waste pectin extraction process flow chart.

\section{Pectin extraction}

Pectin in dry lemon waste was extracted utilizing unadulterated refined water or an arrangement of citric acid at distinctive concentrations of 6,8 , and $10 \%(\mathrm{w} / \mathrm{v})$ at $85{ }^{\circ} \mathrm{C}$ for $3 \mathrm{~h}$ (dry lemon waste to water $1: 10 \mathrm{w} / \mathrm{v})$. The extricated samples were then centrifuged for $15 \mathrm{~min}$ at 4,500 rpm, and the obtained supernatant was dialyzed against refined water for a day, utilizing a dialysis tube with the atomic weight cut off $12,400 \mathrm{Da}$ (Sigma-Aldrich) (17). The dialyzed samples were centrifuged $(4,500$ $\mathrm{rpm})$, the supernatants were accumulated and accelerated with $4 \mathrm{~mL}$ of ethanol (96\% purity, 1:3 $\mathrm{v} / \mathrm{v}$ ) and cooled overnight at $25{ }^{\circ} \mathrm{C}$. After centrifugation, the supernatant was disposed of, and the coagulated accelerates were accumulated and cleaned with ethanol ( $96 \%$ purity) and, after that, centrifuged once more. Finally, the accelerates were hot air-dried at $60^{\circ} \mathrm{C}$, ground, and passed through a 60 mesh analysis to get pectin powder. The amount of the extracted pectin was determined according to Eq. (1). 
Amount of pectin $=\frac{\text { Mass of pectin }(\mathrm{g})}{\text { Massof dry lemonwaste }(\mathrm{g})} \times 100 \%$

\section{Determination of Moisture and Ash contents}

Moisture and ash contents were decided to agree to the strategy of AOAC (18). Moisture content: $1 \mathrm{~g}$ of the sample was weighed and dried by employing an electric oven at $105^{\circ} \mathrm{C}$ for $12 \mathrm{~h}$ to a constant weight. The weight loss was taken and calculated as a percentage of moisture (\%).

Ash content: $2 \mathrm{~g}$ of the sample was weighed and burned in a furnace at $600{ }^{\circ} \mathrm{C}$ for $5 \mathrm{~h}$ and the remaining was weighed, and the percentage of ash content (\%) was calculated.

Determination of the Degree of Esterification (DE)

Titration procedure: The titration strategy was employed to decide the DE of pectin according to USP 30-NF 23 (19). The pectin powder of $60 \mathrm{mg}$ was dissolved using $30 \mathrm{~mL}$ of carbon dioxide-free deionized water for $20 \mathrm{~min}$ at $50{ }^{\circ} \mathrm{C}$ and after that cleared out to cool. After 3 drops of phenolphthalein were added, the solution was titrated with $0.2 \mathrm{~N}$ $\mathrm{KOH}$ concentrations (A). Additionally, $20 \mathrm{~mL}$ of $0.2 \mathrm{~N}$ $\mathrm{KOH}$ was added and blended at room temperature for $25 \mathrm{~min}$. Subsequently, $30 \mathrm{~mL}$ of $0.15 \mathrm{~N} \mathrm{HCl}$ solutions were added and blended until the pink was blurred. The extra 3 drops of phenolphthalein were added and, after that titrated with $0.2 \mathrm{~N} \mathrm{KOH}$ until the endpoint was indicated $(B)$. The percentage (\%) degree of esterification (DE) was calculated using Eq (2).

$$
\text { Degree of esterification }(D E)=\frac{B}{(B+A)} \times 100 \%
$$

\section{Fourier Transform Infrared Spectroscopy (FT-IR)}

The powder of pectins and citrus pectin were dried for a day and blended with spectroscopic-grade $\mathrm{KBr}$. The sample pectin was then put into the $\mathrm{KBr}$ crucible. The infrared spectra were measured on a Bruker-Tensor 30 FT-IR spectrometer, utilizing MIRATR mode. The 64 filters at $4 \mathrm{~cm}^{-1}$ resolution were taken from $4000-400 \mathrm{~cm}^{-1}$. The top zone's proportion at $1725 \mathrm{~cm}^{-1}$ over the entirety of the 2 top zones at 1725 and $1600 \mathrm{~cm}^{-1}$ (relegated to the retention of esterified and non-esterified carboxyl bunches, separately) was determined to \% degree of esterification utilizing OPUS software version 8.3 (20).

\section{Determination of protein content}

Protein substance was analyzed, agreeing with the Bradford's strategy (21). The sample was arranged and diluted using refined water to get a concentration of $4.50 \mathrm{mg} / \mathrm{mL}$. The Bradford buffer solution was added (counting bovine serum egg whites standard solution) and blended well before measuring the absorbance at a wavelength of 595 $\mathrm{nm}$.

\section{Determination of galacturonic acid content}

The galacturonic amount was decided to agree to Blumenkrantz and Asboe-Hansen's (2) strategy, employing a UV-Visible spectrophotometer (PG Instrument, T60, Britain) at the wavelength of 520 $\mathrm{nm}$. The sample concentration of $4.50 \mathrm{mg} / \mathrm{mL}$ was developed in refined water and agitated at $50{ }^{\circ} \mathrm{C}$ for $2 \mathrm{~h}$ and diluted to fit the galacturonic acid standard interval. The diluted sample and standard solutions were blended with $10.5 \mathrm{mM}$ tetraborate in concentrated sulfuric acid and, after that, cooled quickly with an ice bath. All solutions were heated for $3 \mathrm{~min}$ at $90^{\circ} \mathrm{C}$ and left out in an ice bath to cool. The $0.2 \%$ m-hydroxy diphenyl reagent was included, and the absorbance was studied after color improvement for $15 \mathrm{~min}$.

\section{Determination of total sugar content}

The phenol- $\mathrm{H}_{2} \mathrm{SO}_{4}$ was utilized to decide the whole sugar substance as depicted by Lim et al. (22). A sample of $20 \mathrm{mg}$ was weighed and hydrolyzed with $1.5 \mathrm{~mL}$ of $75 \% \mathrm{H}_{2} \mathrm{SO}_{4}$ for $25 \mathrm{~min}$ at $25{ }^{\circ} \mathrm{C}$. After diluting with $10 \mathrm{~mL}$ of refined water, $3 \mathrm{~mL}$ of the diluted sample was pipetted into a test tube and blended with $60 \mu \mathrm{L}$ of $85 \%$ phenol. The concentrated sulfuric acid was added quickly and leftover for 20 min before reading the absorbance at $490 \mathrm{~nm}$, employing a UV-Visible spectrophotometer. The glucose standard bent was plotted to compare the whole sugar as glucose equivalence.

\section{Determination of mineral content}

The mineral substance was decided by inductively coupled plasma optical emission spectrometer (ICPOES) (Perkin Elmer, Optima 8000, and Italy) and CHNS/O analyzer (Thermo Logical, Streak 2000, and the UK).

\section{Determination of monosaccharides}

The pectin sample was hydrolyzed with $1.5 \mathrm{M}$ sulfuric acid solution for $3 \mathrm{~h}$ at $90^{\circ} \mathrm{C}$ and diluted with refined water. The monosaccharide hydrolyzates were sifted through a $0.4 \mu \mathrm{m}$ film, and the volume of $20 \mu \mathrm{L}$ was infused onto a highperformance anion-exchange chromatography (HPAEC) apparatus (Dionex, ICS-2500, USA) isolated by CarboPac PA20 (160 $\mathrm{mm} \times 4 \mathrm{~mm})$ column with an electrochemical indicator (20). The $260 \mathrm{mM} \mathrm{KOH}$ and deionized water proportion was $2 / 23$ to $0 / 100$ to angle elute at the stream rate of $0.3 \mathrm{~mL} / \mathrm{min}$ for 1 hour. Monosaccharides' types and concentrations were recognized by comparison with a blend of monosaccharides (glucose, galactose, arabinose, mannose, xylose, and fructose). 
Determination of molecular weight distribution

The sample was arranged by dissolving in deionized water to the concentration of $5.5 \mathrm{mg} / \mathrm{mL}$ at $60^{\circ} \mathrm{C}$ for $4 \mathrm{~h} \mathrm{(22)}$ and added with potassium chloride $(\mathrm{KCl})$ and ammonium acetate $\left(\mathrm{NH}_{4} \mathrm{CH}_{3} \mathrm{CO}_{2}\right)$ to obtain $100 \mathrm{mM}$ of each. A filter paper was used to filter a solution and the atomic weight was measured by high-performance size exclusion chromatography (HPSEC, Water 3754, Divisions module, Waters enterprise, Italy) utilizing multi-point laser light scrambling and refractive index (RI, Waters 4241, Waters organization, Italy) detectors. The $30 \mu \mathrm{L}$ of the volume was infused onto Ultra hydrogel 300 columns (Waters Enterprise, USA). A blend of 90

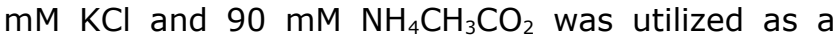
versatile stage with a stream rate of $0.5 \mathrm{~mL} / \mathrm{min}$, and all information was utilized for atomic weight calculation.

\section{Determination of rheological measurement}

The samples were decided on a modular Compact Rheometer: MCR63 (Anton Paar, France), utilizing RheoPlus Rheometer program version 4.52. A cone and plate geometry with a distance across $40 \mathrm{~mm}$ was utilized for oscillatory estimations. The estimations were kept up at room temperature and subjected to the recurrence of $1.0 \mathrm{~Hz}$ using a strain of $3.0 \%$. The samples of $5 \%(\mathrm{w} / \mathrm{v})$ were arranged by dissolving in refined water for $15 \mathrm{~min}$ at $60^{\circ} \mathrm{C}$ (23). After cooling, $0.3 \mathrm{M} \mathrm{CaCl}_{2}$ was included and blended altogether. All samples (with and without $0.3 \mathrm{M} \mathrm{CaCl}_{2}$ ) were stored at $25^{\circ} \mathrm{C}$ for a half a day before the measurement.

\section{Statistical analysis}

All the experiments were carried out in triplicate at the time $(60,120$, and $180 \mathrm{~min})$, temperature $(70$, 90 , and $\left.110^{\circ} \mathrm{C}\right)$ and Citric acid $(6,8,10 \mathrm{v} / \mathrm{v} \%)$, and the analyses of Variance (ANOVA) were carried on by Duncan's and Tukey's methods applying SPSS (Statistical Package for the Social Sciences) version 25. Duncan's and Tukey's tests were accomplished to examine the substantial changes between the mean values for treatments $(P<5 \%)$ and standard deviation (24). The result was indicated in supplementary materials for citric acid extraction (Tables 1-5).

\section{RESULTS AND DISCUSSION}

\section{Water and acid-extracted pectin}

The impression of water and acid-extracted pectin from lemon waste and its DE are indicated in Table 1 . The values showed that the maximum yield of pectin $(20.8 \%)$ and DE $(47.8 \%)$ of extracted pectin were found by water extraction than those of citric acid extractions. It was discovered that acid extractions $(6,8$, and $10 \%)$ significantly diminished the degree of esterification values to 45.6, 33.6, and $25.4 \%$, respectively. It was described that the higher pectin substance was found from fruits and leaves using acid treatment at higher temperature since this condition probable release pectin substance from the cell wall of the plant (25), while other authors found that acidic solvents at high temperature degraded pectin (26). In this study, the result was in correspondence with the previous finding. The Statistical data analysis using Duncan's and Tukey's methods applying SPSS version 25 was also indicated in supplementary materials (Table 1$6)$.

A diminishment in methoxyl group and pectin yield was detected. As a result of the depolymerization of acid, de-esterification could be due to higher temperature and long-time technique (27). Therefore, the extract found from water extraction was further examined concerning the maximum yield.

Table 1: Effect of water and acid extraction on yield and DE of lemon waste pectin.

\begin{tabular}{|c|c|c|}
\hline $\begin{array}{l}\text { Solution } \\
\left(\text { at } 90^{\circ} \mathrm{C}\right)\end{array}$ & $\begin{array}{l}\text { Yield of pectin } \\
\text { ( } \%, \text { dry basis) }\end{array}$ & DE (\%) \\
\hline $10 \%$ Citric Acid & $10.0 \pm 0.38 w$ & $24.3 \pm 1.11 \mathrm{w}$ \\
\hline 8\% Citric Acid & $16.5 \pm 0.07 x$ & $31.4 \pm 1.86 x$ \\
\hline 6\% Citric Acid & $12.5 \pm 0.33 y$ & $44.7 \pm 0.89 y$ \\
\hline Purified water & $20.7 \pm 0.23 z$ & $48.3 \pm 0.29 z$ \\
\hline
\end{tabular}

The different letters $w x, y$ and $z$ in the same column are significantly different $(P<5 \%)$

\section{Characterization of extracted pectin}

The extracted pectin was analyzed for composition as indicated in Table 2. It was determined that the pectin extracted in dry lemon waste contained $5.7 \%$ of moisture content, $3.6 \%$ of ash content, and $2.4 \%$ of protein content. It consisted of the higher value of galacturonic acid $61.2 \%$ and $19.3 \%$ of low sugar contents. The total sugar amount was similar to the pectin of citrus fruits, around 14.6 to $20.50 \%$ described by Liew et al. (2). The other components, including mannose, fructose, galactose, glucose, arabinoses, and xylose, also existed with a few minerals. The observation results explicated that polyose in the extract was highly galacturonic acid and small amounts of neutral sugar, commonly found in pectin structure. Depend on the DE value $(48.3 \%)$ and composition, the extracted pectin in this research shown that it could be grouped as low methoxyl pectin since its DE is below $50 \%$ (6). The low DE result was not coherent with the finding of $64 \%$ DE as reported by Yeoh et al. (4). Although the $D E$ of pectin is based on the origin (source) and extraction methods and conditions, it generally diminishes with the rise of adulthood level (10). 
The FT-IR spectrum has illustrated pectin's characteristics extracted from lemon wastes by comparison to other citrus pectins. Figure 1 indicates that the wavenumber interval of 1680 1760 and $1540-1680 \mathrm{~cm}-1$ was the extending of the ester carbonyl group $(\mathrm{C}=\mathrm{O})$ and carboxyl ion groups (COO-), respectively, when equated with the information described $(4,13)$. It was shown that the citrus pectin addressed under the area the spectrum of $\mathrm{C}=\mathrm{O}$ and $\mathrm{COO}-$. The peak reign of $\mathrm{C}=\mathrm{O}$ diminished, in conformity with a diminish of a $D E$, while the peak reign of COO- raised (10). The spectrum of lemon waste pectin was similar to that of $55-70 \%$ degree of esterification of citrus pectin, proposing that the extracted pectin might have a similar percentage of a DE. Nevertheless, when decided by the FT-IR method, the intensity of the peak reign of $\mathrm{C}=\mathrm{O}$ was estimated and determined as $46.8 \%$ of the degree of esterification, roughly close to $47.5 \%$ degree of esterification detected by the titrimetric procedure (Table 2), which affirmed that pectin in lemon wastes should be LMP.
Table 2: Chemical composition of extracted pectin.

\begin{tabular}{|c|c|}
\hline $\begin{array}{l}\text { Chemical } \\
\text { composition }\end{array}$ & $\begin{array}{l}\text { Content (\%, } \\
\text { dry basis) }\end{array}$ \\
\hline Moisture & $5.5 \pm 0.43$ \\
\hline Ash & $3.7 \pm 0.03$ \\
\hline Protein & $2.8 \pm 0.12$ \\
\hline Galacturonic acid & $63.2 \pm 0.74$ \\
\hline $\begin{array}{c}\text { Total sugar } \\
\text { Monosaccharides }\end{array}$ & $17.4 \pm 0.76$ \\
\hline Arabinose & $2.7 \pm 0.20$ \\
\hline Galactose & $2.3 \pm 0.01$ \\
\hline Glucose & $1.4 \pm 0.09$ \\
\hline Mannose & $0.4 \pm 0.01$ \\
\hline Fructose & $0.4 \pm 0.05$ \\
\hline Xylose & $0.1 \pm 0.01$ \\
\hline \multicolumn{2}{|l|}{ Minerals } \\
\hline $\mathrm{K}$ & $1.23 \pm 0.01$ \\
\hline $\mathrm{N}$ & $0.85 \pm 0.02$ \\
\hline $\mathrm{Ca}$ & $0.75 \pm 0.03$ \\
\hline $\mathrm{Si}$ & $0.075 \pm 0.02$ \\
\hline$P$ & $0.01 \pm 0.02$ \\
\hline $\mathrm{Mn}$ & $0.011 \pm 0.00$ \\
\hline $\mathrm{S}$ & $<0.01$ \\
\hline
\end{tabular}

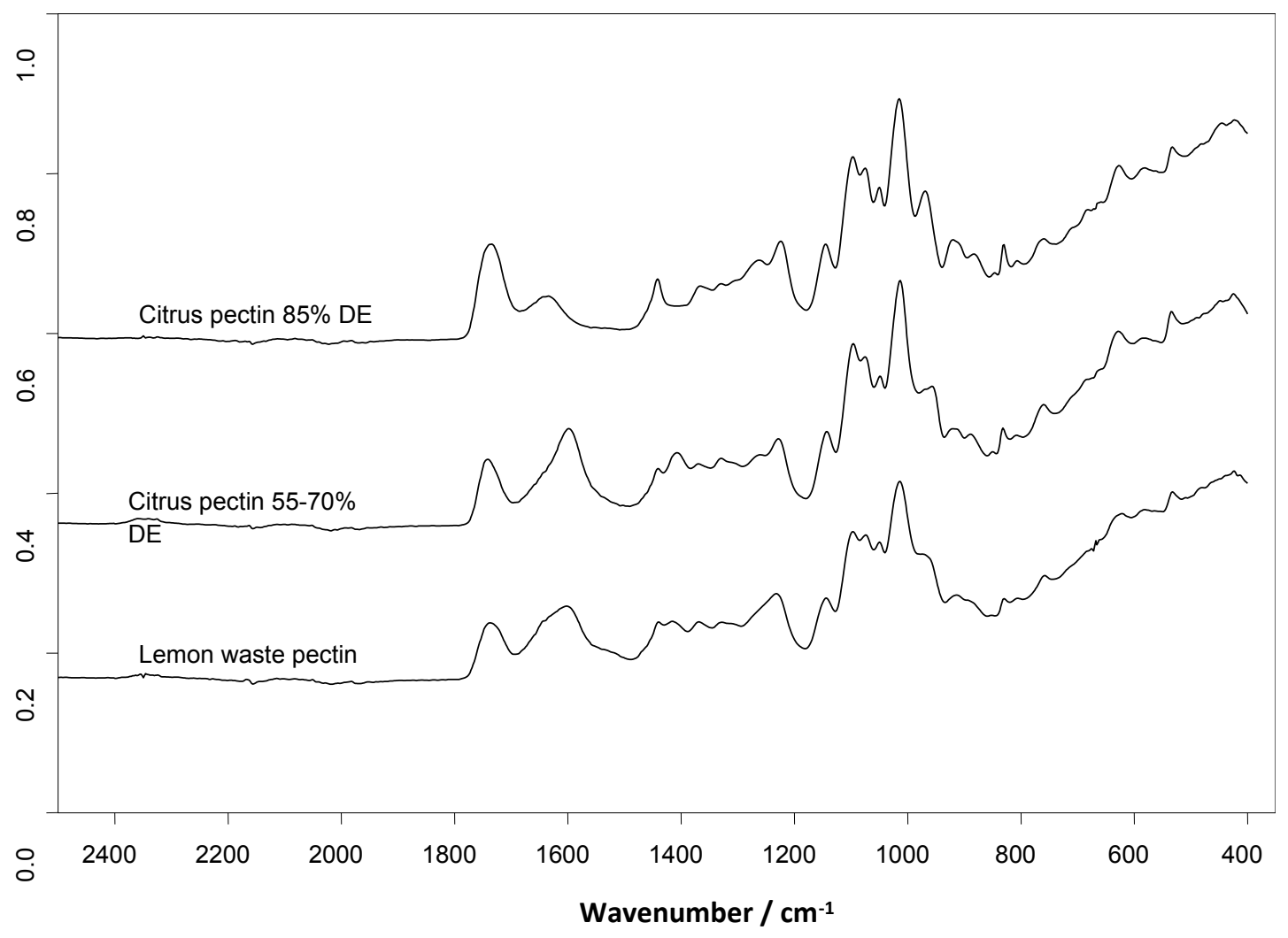

Figure 2: FT-IR Spectrum of lemon waste pectin and citrus pectin. The y axis is absorbance. 


\section{Molecular weight distribution}

The molecular weight dispersion chromatogram of lemon waste pectin run by HPSEC with double detectors is indicated in Figure 2. The light dispersion (LD) indicated only one large dispersion part as a function of time, while the refractive index (RI) indicated two parts of unlike molecular size. This is due to a common argument that the LD signal is low sensitive to minor molecular dispersion. The large intensity signal observed by LD was a potential dominant large molar weight constituent galacturonic units of pectin polysaccharides in concurrence with a high peak by RI at a retention time of roughly $20 \mathrm{~min}$. The littler elution peak indicated by RI around 30 min may be led to a little number of protein atoms that are ordinarily combined in polysaccharides. It was taken note that the mean atomic weight (Aw) of lemon wastes pectin was $2060 \mathrm{kDa}$, much higher than that of the LM of citrus pectin extending from 110 - $290 \mathrm{kDa}$, and the polydispersity record $(\mathrm{Mw} / \mathrm{Mn})$ was 4.31 , too more prominent than $1.74-2.60$ in that report measured by HPSEC chromatography methods (15, 20). The molecular (atomic) weight was higher than already detailed in LMP extricated from okra fruits which extending from $700-1700 \mathrm{kDa}$ (28). The wide atomic mass with Aw/Mn of 4.41 of extricated lemon wastes pectin was likely due to the natural development and the impact of extraction conditions.
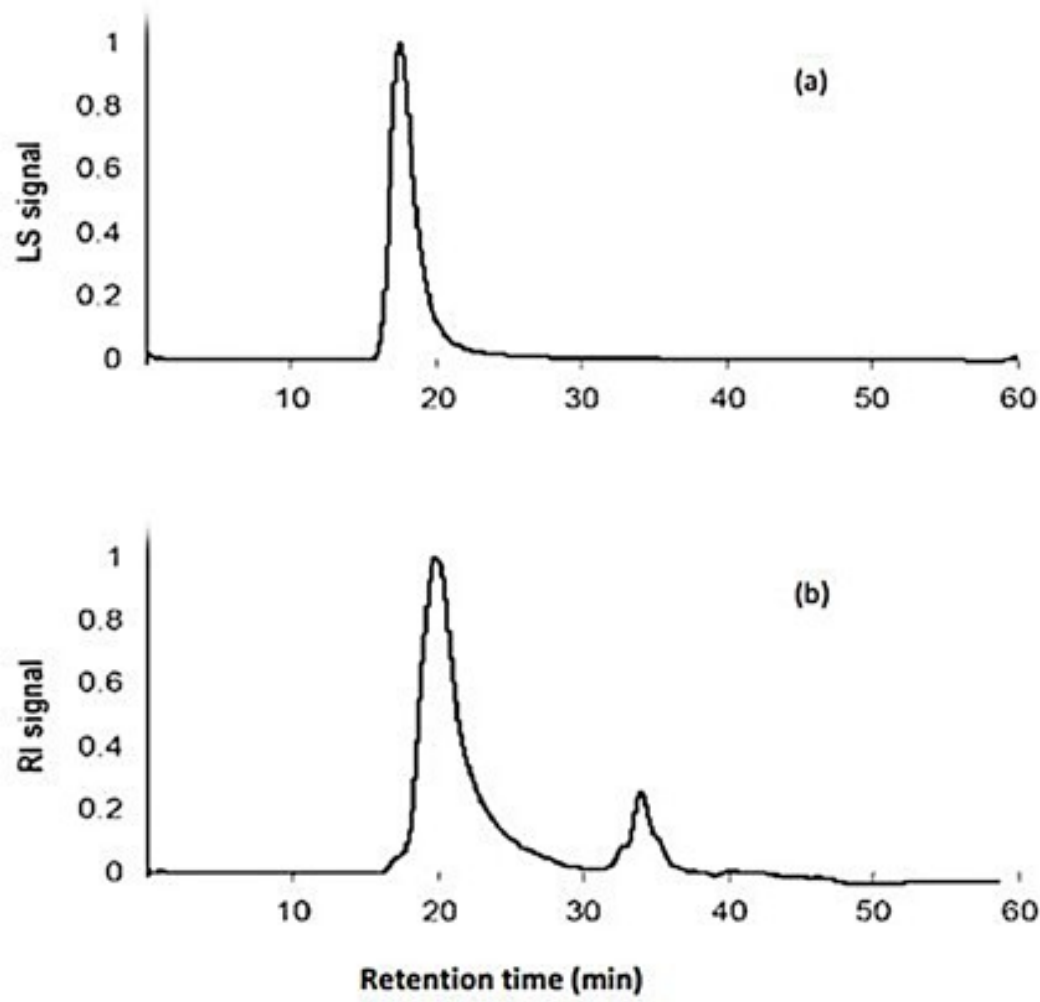

Figure 3: HPSEC chromatogram of lemon waste pectin from 2 detectors: (a) Light scattering (LS) and (b) refractive index $(\mathrm{RI})$.

\section{Rheological properties}

The rheological properties of lemon waste pectin $(4.5 \% \mathrm{w} / \mathrm{v})$ with and without the addition of calcium chloride have appeared in Figure 3. In Figure 3(a), the fast diminishment in complex viscosity was detected with expanding frequency, clarified strong shear diminishment stream characteristics. A better complex viscosity of lemon waste pectin with calcium chloride was recorded as a function of particular recurrence than that without calcium chloride, which shown that the existence of calcium ion affected intermolecular systems of pectin substances. When assist expanded in recurrence, the significantly diminished in complex thickness to about zero value was found likely due to shear misshapen within the consistent period. 


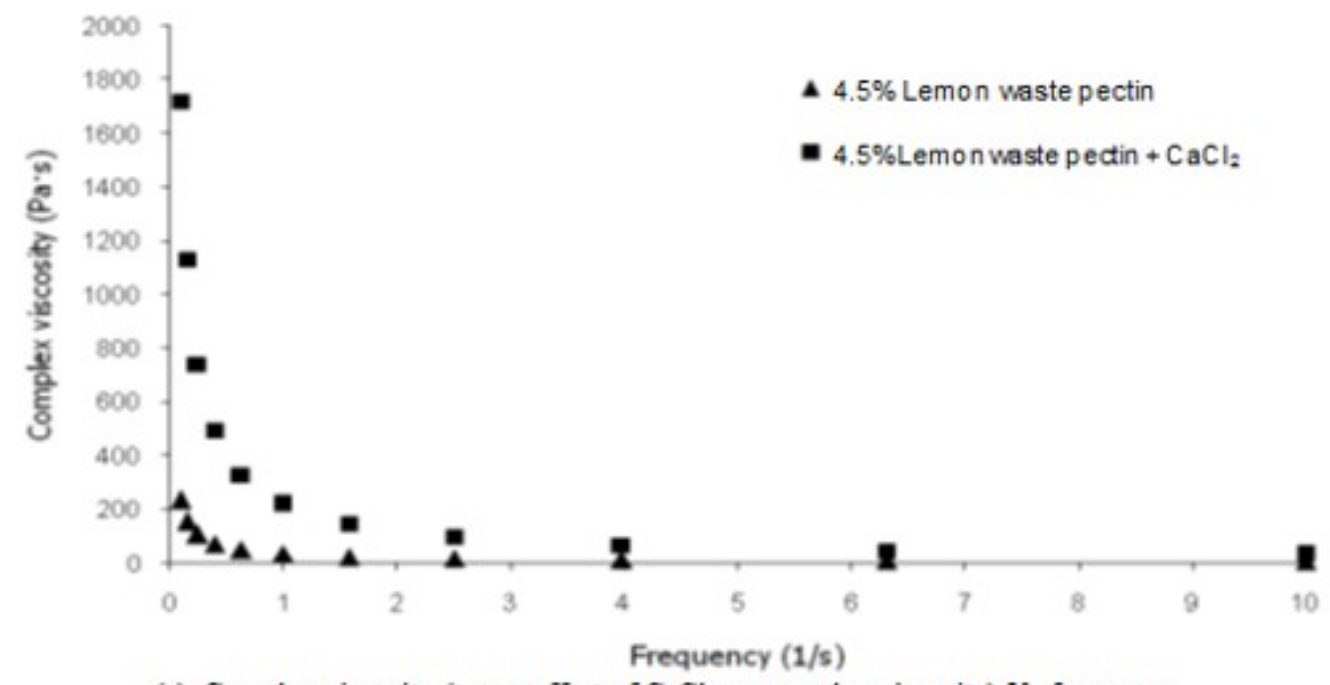

(a) Complex viscosity (to see effect of $\mathrm{CaCl}_{2}$ on complex viscosity) $\mathrm{Vs}$ frequency

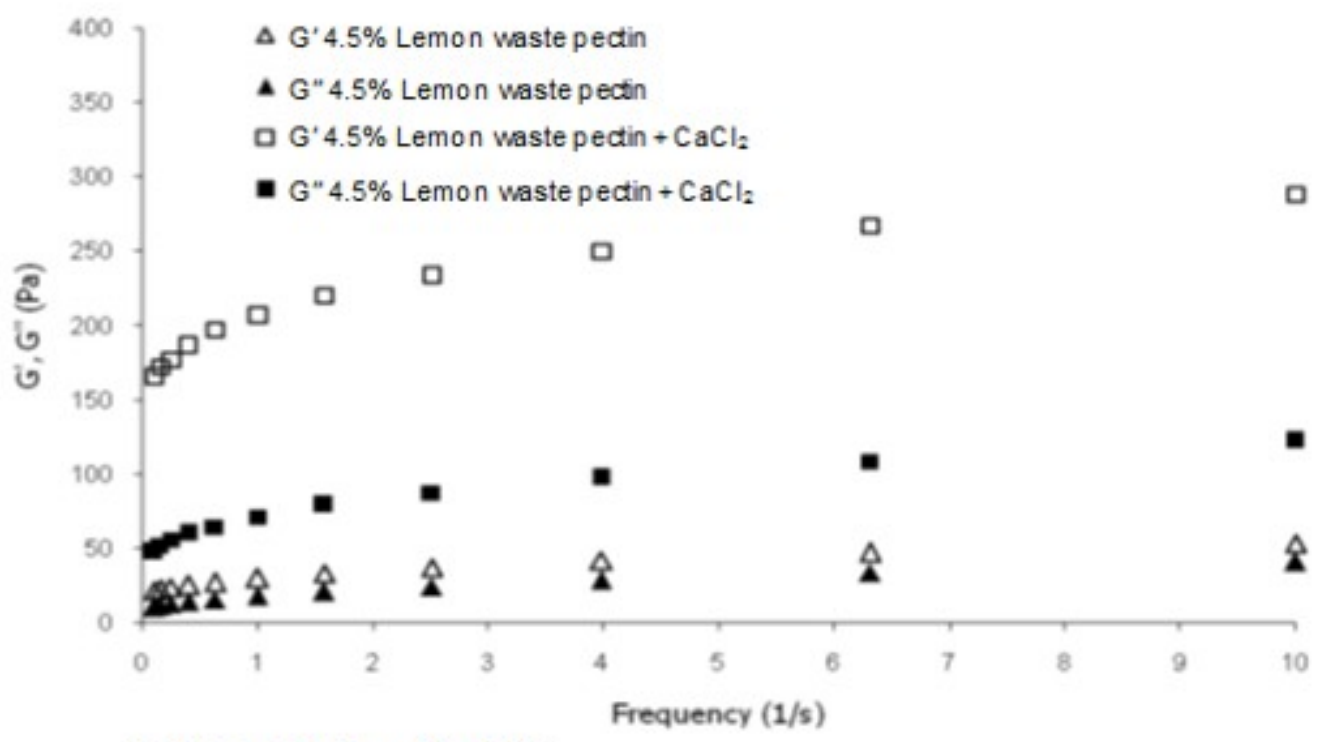

(b) Effect of $\mathrm{CaCl}_{2}$ on $\mathrm{G}^{\prime}$ and $\mathrm{G}^{\prime \prime}$

Figure 4: Rheological properties of lemon waste pectin.

Figure 3(b) outlines the capacity $\left(\mathrm{G}^{\prime}\right)$ and loss $\left(\mathrm{G}^{\prime \prime}\right)$ moduli in lemon waste pectin with and without the inclusion of calcium chloride. The clear recurrence tests appeared a higher $\mathrm{G}^{\prime}$ than $\mathrm{G}^{\prime \prime}$ without hybrid, within the energetic run between 0 and $10 \mathrm{~Hz}(1 / \mathrm{s})$, supporting the marvel of gel-like behavior at minimum frequencies. It was detected that lemon waste pectins (with and without calcium chloride ions) were gathered to be weak-gels about G' cross all over G" and subordinate on the powerless recurrence within the experiment $(21,29)$. The intelligence between carboxyl bunches on the most chain of LMP and divalent cations ( $\mathrm{Ca} 2+)$ are critical for cross-bridge gelation through the component called "egg-box" due to the affiliation of intermolecular intersection zones between the smooth homogalacturonan area of diverse chains
(20). The rheological outcome confirmed that the extractable pectin in lemon waste was LMP, in which pectin polymers ionically cross-linked through free carboxyl chain and divalent cations.

\section{CONCLUSIONS}

In this work, the composition and characteristics of water-extractable pectin obtain from lemon wastes were studied. The hot water extraction gave better results than a hot acidic extraction using citric acid, since it produces the highest pectin yield. The extracted pectin was mainly composed of galacturonic acid and considered as low methoxyl pectin, based on a low degree of esterification values as it was detected by FT-IR fingerprint. The HPSEC analysis clarified those pectin 
polysaccharides had high molecular weight, which enabled interaction with calcium ions as detected by rheological analysis. These results propose that lemon waste is a good source of gelling pectin that could be employed in food and non-food products.

The yield of water-extracted pectin is higher than acid-extracted pectin.

\section{ACKNOWLEDGEMENTS}

The author expresses his gratitude to Jimma University, Jimma Institute of Technology, Addis Ababa institute of technology for supporting this research. Thanks are extended to the School of Chemical Engineering staff members and technicians and the department of chemistry for their support.

\section{CONFLICT OF INTEREST}

The author announces that there is no conflict of interest.

\section{FUNDING}

This research was supported by the School of chemical engineering, Jimma Institute of Technology (JiT), and Addis Ababa Institute of Technology.

\section{REFERENCES}

1. Hosseini SS, Khodaiyan F, Kazemi M, Najari Z. Optimization and characterization of pectin extracted from sour orange peel by ultrasound assisted method. International Journal of Biological Macromolecules. 2019 Mar;125:621-9. <DOI>.

2. Liew SQ, Chin NL, Yusof YA. Extraction and Characterization of Pectin from Passion Fruit Peels. Agriculture and Agricultural Science Procedia. 2014;2:231-6. <DOI>.

3. Kpodo FM, Agbenorhevi JK, Alba K, Bingham RJ, Oduro IN, Morris GA, et al. Pectin isolation and characterization from six okra genotypes. Food Hydrocolloids. 2017 Nov;72:323-30. <DOI>.

4. Yeoh S, Shi J, Langrish TAG. Comparisons between different techniques for water-based extraction of pectin from orange peels. Desalination. 2008 Jan;218(1-3):229-37. <DOI>

5. Grassino AN, Barba FJ, Brnčić M, Lorenzo JM, Lucini L, Brnčić SR. Analytical tools used for the identification and quantification of pectin extracted from plant food matrices, wastes and by-products: A review. Food Chemistry. 2018 Nov;266:47-55. $\leq \mathrm{DOI}>$.
6. Hosseini SS, Khodaiyan F, Yarmand MS. Aqueous extraction of pectin from sour orange peel and its preliminary physicochemical properties. International Journal of Biological Macromolecules. 2016 Jan;82:920-6. <DOI>.

7. Kazemi M, Khodaiyan F, Hosseini SS. Utilization of food processing wastes of eggplant as a high potential pectin source and characterization of extracted pectin. Food Chemistry. 2019

Oct;294:339-46. <DOI>.

8. Lu J, Li J, Jin R, Li S, Yi J, Huang J. Extraction and characterization of pectin from Premna microphylla Turcz leaves. International Journal of Biological Macromolecules. 2019 Jun;131:323-8. <DOI>.

9. Kurita O, Fujiwara T, Yamazaki E. Characterization of the pectin extracted from citrus peel in the presence of citric acid. Carbohydrate Polymers. 2008 Nov; 74(3):725-30. <DOI $>$.

10. Happi Emaga T, Ronkart SN, Robert C, Wathelet $B$, Paquot $M$. Characterisation of pectins extracted from banana peels (Musa AAA) under different conditions using an experimental design. Food Chemistry. 2008 May;108(2):463-71. <DOI>.

11. Yapo BM. Pectin quantity, composition and physicochemical behaviour as influenced by the purification process. Food Research International. 2009 Oct;42(8):1197-202. <DOI>.

12. Xue Z, Zhang X, Zhang Z, Liu J, Wang Y, Chen $D$, et al. Optimization of pectin extraction from citrus peel by response surface methodology. Food Science. 2011;18:128-32.

13. Vriesmann LC, de Mello Castanho Amboni RD, de Oliveira Petkowicz CL. Cacao pod husks (Theobroma cacao L.): Composition and hot-watersoluble pectins. Industrial Crops and Products. 2011 Jul;34(1):1173-81. <DOI>.

14. Alba K, Laws AP, Kontogiorgos V. Isolation and characterization of acetylated LM-pectins extracted from okra pods. Food Hydrocolloids. 2015 Jan;43:726-35. <DOI >.

15. Bagde PP, Dhenge S, Bhivgade S. Extraction of pectin from orange peel and lemon peel. International Journal of Engineering Technology Science and Research. 2017;4(3):1-7.

16. Kulkarni SG, Vijayanand P. Effect of extraction conditions on the quality characteristics of pectin from passion fruit peel (Passiflora edulis f. flavicarpa L.). LWT - Food Science and Technology. 2010

Sep;43(7):1026-31. <DOI>

17. Forni E, Penci M, Polesello A. A preliminary 
characterization of some pectins from quince fruit (Cydonia oblonga Mill.) and prickly pear (Opuntia ficus indica) peel. Carbohydrate Polymers. 1994 Jan;23(4):231-4. <DOI>.

18. Shafie MH, Yusof R, Gan C-Y. Deep eutectic solvents (DES) mediated extraction of pectin from Averrhoa bilimbi: Optimization and characterization studies. Carbohydrate Polymers. 2019 Jul;216:30311. <DOI $>$.

19. Yapo BM, Lerouge $P$, Thibault J-F, Ralet M-C. Pectins from citrus peel cell walls contain homogalacturonans homogenous with respect to molar mass, rhamnogalacturonan I and rhamnogalacturonan II. Carbohydrate Polymers. 2007 Jun;69(3):426-35. <DOI>.

20. Alba K, MacNaughtan W, Laws AP, Foster TJ, Campbell GM, Kontogiorgos V. Fractionation and characterisation of dietary fibre from blackcurrant pomace. Food Hydrocolloids. 2018 Aug;81:398-408. $\leq \mathrm{DOI}>$.

21. Rahmani Z, Khodaiyan F, Kazemi M, Sharifan A. Optimization of microwave-assisted extraction and structural characterization of pectin from sweet lemon peel. International Journal of Biological Macromolecules. 2020 Mar;147:1107-15. <DOI>.

22. Lim J, Yoo J, Ko S, Lee S. Extraction and characterization of pectin from Yuza (Citrus junos) pomace: A comparison of conventional-chemical and combined physical-enzymatic extractions. Food Hydrocolloids. 2012 Oct;29(1):160-5. <DOI>.

23. Liu Y, Shi J, Langrish T. Water-based extraction of pectin from flavedo and albedo of orange peels. Chemical Engineering Journal. 2006 Jul
$15 ; 120(3): 203-9 . \leq$ DOI $>$.

24. Ros JM, Schols HA, Voragen AGJ. Extraction, characterisation, and enzymatic degradation of lemon peel pectins. Carbohydrate Research. 1996 Feb;282(2):271-84. <DOI>.

25. Adetunji LR, Adekunle A, Orsat V, Raghavan V. Advances in the pectin production process using novel extraction techniques: A review. Food Hydrocolloids. 2017 Jan;62:239-50. <DOI>.

26. Liew SQ, Ngoh GC, Yusoff R, Teoh WH. Sequential ultrasound-microwave assisted acid extraction (UMAE) of pectin from pomelo peels. International Journal of Biological Macromolecules. 2016 Dec;93:426-35. <DOI>.

27. Muthusamy S, Manickam LP, Murugesan V, Muthukumaran C, Pugazhendhi A. Pectin extraction from Helianthus annuus (sunflower) heads using RSM and ANN modelling by a genetic algorithm approach. International Journal of Biological Macromolecules. 2019 Mar;124:750-8. <DOI>.

28. Yuliarti O, Goh KKT, Matia-Merino L, Mawson J, Brennan C. Extraction and characterisation of pomace pectin from gold kiwifruit (Actinidia chinensis). Food Chemistry. 2015 Nov;187:290-6. $\leq \mathrm{DOI}$.

29. Colodel C, Vriesmann LC, Lucia de Oliveira Petkowicz C. Rheological characterization of a pectin extracted from ponkan (Citrus reticulata blanco cv. ponkan) peel. Food Hydrocolloids. 2019 Sep;94:326-32. <DOI $>$. 
